\title{
Crop Calendar Mapping of Bangladesh Rice Paddy Field with ALOS-2 ScanSAR Data
}

\author{
Md. Rahedul Islam \\ Department of Geography and Environment, Pabna University of Science and Technology, Pabna, Bangladesh \\ Email: rahe_ge@pust.ac.bd
}

How to cite this paper: Islam, Md.R. (2021) Crop Calendar Mapping of Bangladesh Rice Paddy Field with ALOS-2 ScanSAR Data. Advances in Remote Sensing, 10, 115-129.

https://doi.org/10.4236/ars.2021.103008

Received: September 5, 2021

Accepted: September 27, 2021

Published: September 30, 2021

Copyright $\odot 2021$ by author(s) and Scientific Research Publishing Inc. This work is licensed under the Creative Commons Attribution International License (CC BY 4.0).

http://creativecommons.org/licenses/by/4.0/ (c) (i) Open Access

\begin{abstract}
Rice paddy mapping with optical remote sensing is challenging in Bangladesh due to the heterogeneous cropping pattern, fragmented field size and cloud cover during the growing period. The high-resolution Synthetic Aperture Radar (SAR) sensor is the potential alternate to mapping rice area in Bangladesh. The L-band SAR sensor onboard Advanced Land Observing Satellite (ALOS) acquires multi-polarization and multi-temporal images are a very useful tool for rice area mapping. In this study, we used ALOS-2 ScanSAR dual $(\mathrm{HH}+\mathrm{HV})$ polarized time series data in the study area. We used orthorectification and slope corrected backscatter (sigma-naught) images and median filtering $(3 \times 3)$ window for image processing. The unsupervised classification with the k-means++ algorithm is used for initial clustering (20 categories) of images over the study area. The GPS location of rice paddy field with cropping pattern over study area uses for classifying the different ricegrowing season from the k-means clustering data. The result is compared with the moderate resolution imaging spectroradiometer (MODIS) based rice area and national statistical agricultural yearbook statistics. The results show that, based on the MODIS based rice map, the rice fields can be mapped with a conditional Kappa value of 0.68 and at user's and producer's accuracies of $86 \%$ and $90 \%$, respectively. The large commission error primarily came from confusion between wet season Aus rice and others crop, Aus-Amon and Boro-Aus-Amon cropping pattern because of their similar backscatter amplitudes and temporal similarities in the rice growing season. The relatively high rice mapping accuracy in this study indicates that the ALOS/PALSAR-2 data could provide useful information in rice cropping management in subtropical regions such Bangladesh.
\end{abstract}

\section{Keywords}

K-Means++, Unsupervised Classification, Moderate Resolution Imaging Spectroradiometer (MODIS), Backscatter Co-Efficient, Field Data 


\section{Introduction}

Bangladesh is the $4^{\text {th }}$ largest rice producer, importer and consumer country in the world [1]. The $75 \%$ of total agricultural land used for rice cultivation in the country (BBS). Rice is the staple food and $70 \%$ of total calorie intake come from rice [2]. Due to the drastic population growth (98 billion) growth need $70 \%$ more food in 2050 [3]. But the arable land area of the country is even decreasing over time due to increasing demand for residential and industrial use [4]. Bangladesh also suffers from periodic natural calamities such as drought, flooding, and cyclones. Due to its location in a delta, climate change and associated sea level rise are expected to increase the risk for flooding and salinization of agricultural lands, especially near the southern coast [5] [6]. The rice cultivated areas of Bangladesh is located low-land, flat and inundate areas and these areas are easily damaged by natural disaster likes floods, drought and storms. The country's market economics and food security mainly depend on rice production. Accurate information on rice cultivation extent, rice production and long-term information are very important for the country. There are several attempts have been taken for rice area mapping over the country. The expert opinion, census data and GIS application are the traditional way of rice mapping. But the variation of ricegrowing season and area, it's very difficult to know the exact location of the rice paddy field with the traditional method. The remote sensing application for rice area monitoring and mapping is an efficient and dependable tool for precise and timely information on rice phenology and vegetation development [7]. The optical remote single sensor-based Landsat, AVHRR and MODIS data derived rice area mapping is the most common at global and regional scale [8]. The mix pixel classification is one of the disadvantages for single sensor application. Multi temporal and high-resolution sensor data have been used to overcome such problem [9]. The multi-temporal Landsat 8 NDVI and LST data with CNN algorithm used for mapping rice area in China with very high accuracy [10] [11]. The Landsat TM and OLI data from 1993 to 2016 with NDVI and MNDWI index and masking method have been used for rice area mapping in Southern China region [12]. The moderate resolution imaging spectrometer (MODIS) derived NDVI and spectral matching techniques used rice mapping in Bangladesh with $90 \%$ accuracy [13], optical and radar imagery in South Asia with high accuracy [14]. The land surface water index (LSWI), NDSI, and enhanced vegetation index (EVI) have been used for rice area mapping in regional and global scale [15].

Although optical sensor data are useful to map paddy rice, there is a limitation for data acquisition due to cloud contamination especially like a cloud prone country Bangladesh. Synthetic Aperture Radar (SAR) data have been used to complement the cloud problems of optical sensor images because SAR data are not influenced by weather conditions [16]. Several studies employed SAR data for land cover/land use as well as paddy rice mapping [17] [18] [19] [20]. The synthetic aperture radar (SAR) ALOS/PALSAR data derived multidate variation of horizontal-horizontal polarization and support vector machine (SVM) classifier have been used in south east China [10]. The operational near real time 
rice area mapping with Sentinel-1 data on GEE platforms with random forest classifier with the classification accuracy $0.84 \%$ found in India [21]. The higher resolution and cloud free SAR imagery have been analyzed on GEE platform with random forest classification and showed $90 \%$ accuracy of rice classification in Bangladesh and northeast India [19]. Along with seasonal cloud contamination, the high cropping intensity, diversity and land fragmentation are the challenges to map rice calendar in Bangladesh. The ALOS-2 ScanSAR data emits microwave and receives reflection from ground without other light sources. The frequency of transmission and receiving microwave is L-band and less affected by weather condition. Moreover, L-band microwave can reach to the ground partially penetrating through vegetation to obtain information of vegetation and ground surface. As a result, ALOS-2 could be a very good tool for rice area mapping. In this study, we used high resolution ALOS-2 L band ScanSAR dataset to overcome such problems. The main objective of this study to map rice crop calendar over Bangladesh with ScanSAR dataset. In Bangladesh, along with seasonal cloud contamination, the high cropping intensity, crop diversity and land fragmentation are the challenges to map rice area. Due to the favourable environment for rice cultivation through the year, fertile land and high market demand of rice, rice cultivated three times in a year as single, double and triple crops. The three main rice growing seasons in Bangladesh are December/January to April (Boro Season), April/May to June/July (Aus Season) and July/August to November/December (Amon Season). Moreover, the small farm size, high cropping intensity and frequently changes the rice cultivated field. This study will help to solve the cloud contamination problem and small cropping pattern identification throughout the year in Bangladesh.

\section{Methodology}

\subsection{Data and Study Area}

The main dataset use for this study is ALOS-2 ScanSAR L band multidate data with $50 \mathrm{~m}$ grid. ALOS-2 is a Synthetic Aperture Radar (SAR). The three tiles N23E89 (Dinajpur) with 18 scenes median filtering HH [HV], N25E89 (Rangpur) with 18 scenes median filtering HH [HV], and N26E88 (Satkhira) 12 scene median filtering HH $[\mathrm{HV}]$ have been used in this study (Figure 1(a)). The filed data have been collected over Bangladesh with GPS location and cropping pattern. The MOD13A2 Kalman's filtered rice area map (Islam and Takeuchi, 2019) data have been used for comparison. The FAO crop calendar of Bangladesh, literature review, national and international reports on rice production, expert opinion also used as secondary data for comparison our study result. Bangladesh is one of the largest rice-growing countries in South Asia. It extends from $20^{\circ} 44^{\prime} 00^{\prime \prime}$ to $26^{\circ} 37^{\prime} 51^{\prime \prime} \mathrm{N}$ latitude and from $88^{\circ} 00^{\prime} 14^{\prime \prime}$ to $92^{\circ} 40^{\prime} 08^{\prime \prime} \mathrm{E}$ longitude and covered $148,450 \mathrm{~km}^{2}$ (Figure 1(a)). Physically the country is almost low altitude, relatively flat except the north-eastern and south-eastern hill tracts. Administratively, the country divided into major seven division; Dhaka, Rajshahi, Chittagong, Rangpur, Sylhet, Barisal and Khulna. Climatically, Average annual rainfall 
varies from $1200 \mathrm{~mm}$ in the extreme west to over $4000 \mathrm{~mm}$ in the northeast and temperature $12^{\circ} \mathrm{C}$ in January to $42^{\circ} \mathrm{C}$ in April (BMD). The country's mean annual lake evaporation is approximately $1040 \mathrm{~mm}$, which is about 45 per cent of the mean annual rainfall. There is a huge seasonal variation of the weather parameter especially the temperature and rainfall (Figure 1(b)). There are three major rice growing season in the country. Boro rice season (December/January to March/April) is the second largest by area and accounts for 50\% (4.84 million hectares) of total rice production of the country. It's the highest yield rice producing season, cultivated in summer with fully irrigation and high fertilizer inputs. Aus rice (April/May to July) is smaller rice area, accounts for 9\% (1.04 million hectares) of total production and cultivated in monsoon season. The Aus is cultivated under almost rainfed condition but a great uncertainty due to the flood. Amon rice (July/August to November) is the largest (5.53 million hectares) rice growing season and accounts for $41 \%$ of total rice production. This rice season is a very critical growing period due to the flood in early growing stage and frequent drought in the later growing stage. The FAO rice crop calendar shown in Figure 1(c).

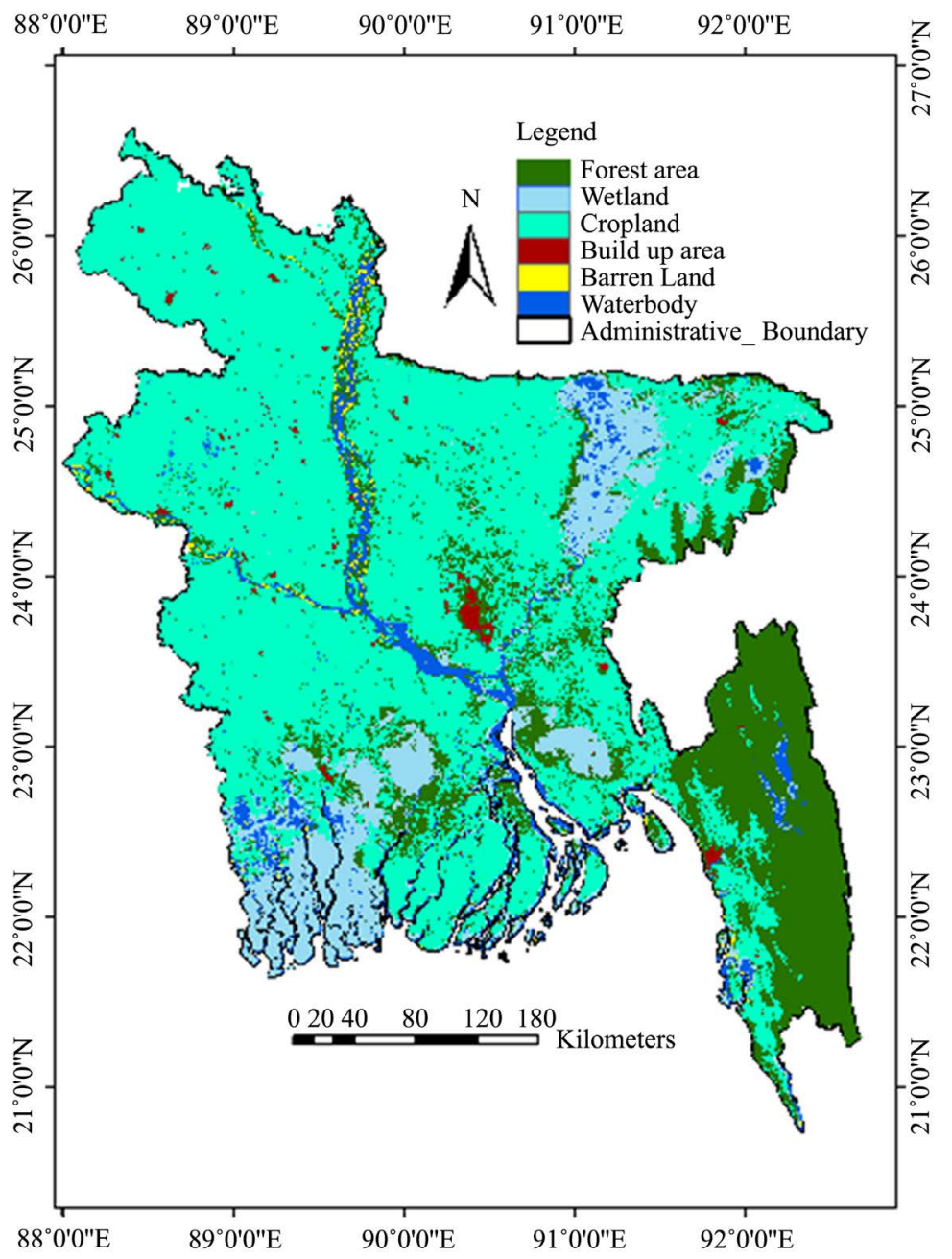

(a) 


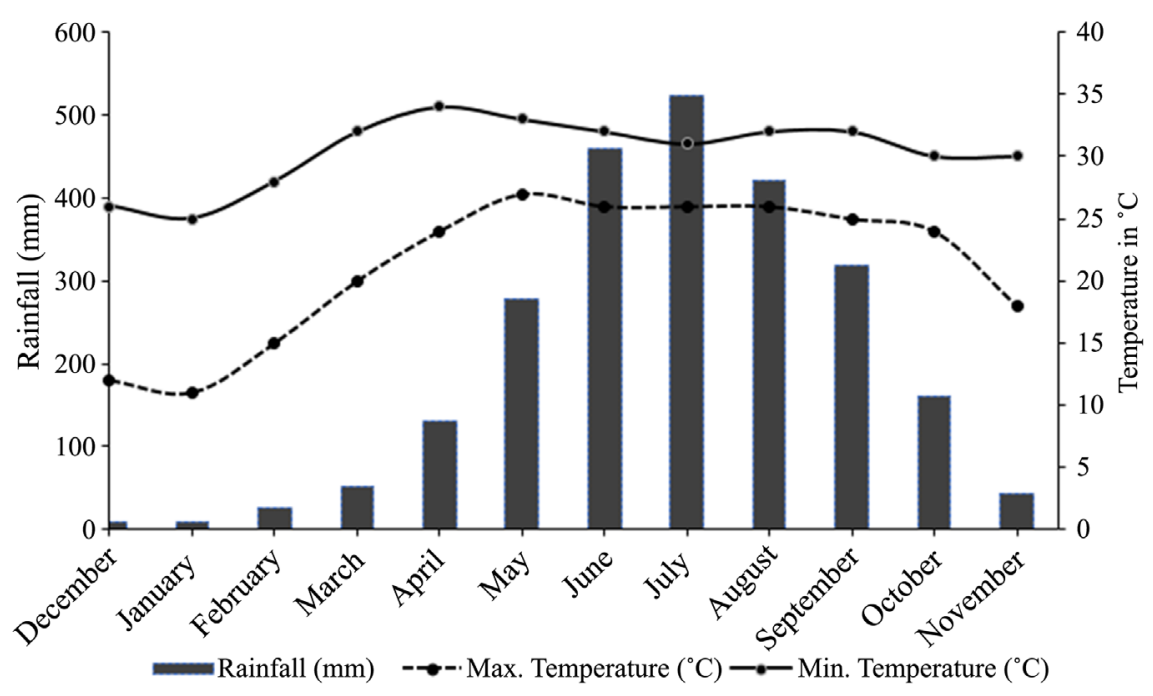

(b)

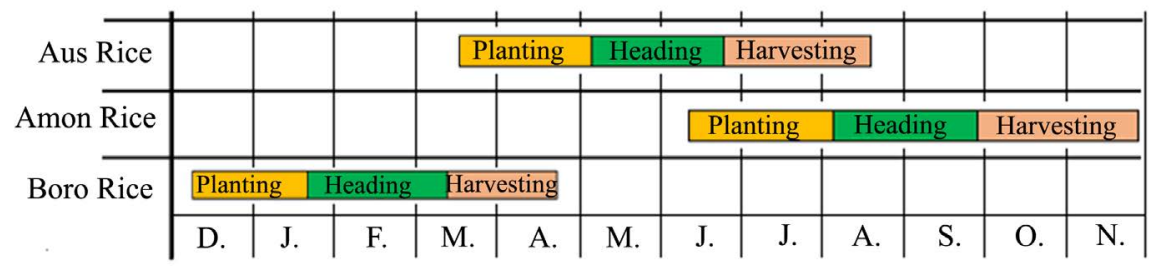

(c)

Figure 1. (a) Geographical location and generalized land use and land cover (LULC) map of the study area from MCD12Q1, Land use and Land Cover Map of Bangladesh; (b) Monthly average minimum and maximum temperature, and rainfall over Bangladesh [22]; (c) Rice paddy crop calendar in the study area [23].

\subsection{Methodology}

The research methodology comprises remote sensing data analysis, field data collection and compare result with relevant sources of data. The ALOS-2 median filtering $\mathrm{HH}[\mathrm{HV}]$ backscattered value can detect the surface inundation condition even vegetated stage of rice growing period (Figure 2). The rice crop cultivation needs some specialize environment for grown up. Before plantation, the cultivated land plough with water and makes muddy wetted. This flooding period for one to week ALOS-2 backscattered shows specular reflection, after plantation and growing stage showed weak backscattered. In the well growing vegetated period, the strong backscatter appears in rice paddy field. After harvesting, the fallow straw field also demonstrates distinguish backscatter value (Figure 2).

In this study we used the median backscatter value for rice paddy detection. Three different regions ALOS-2 ScanSAR images with backscatter value have been used. Initially, we apply orthorectification, slope correction, and select the best available image over the study area. The $\mathrm{DN}$ value of image converted into backscatter sigma naught value and applied median $3 * 3$ median filtering. The annual composite image used for unsupervised K-means++ classification and 
categorized 20 class. We collect the GPS data of rice paddy field with cropping pattern over the study area. We extract the GPS values K-means class and prepared a confusion matrix for rice types identification. With the confusion matrix, we select the seasonal rice crop class (Boro, Aus, and Amon rice). Then, we reclassify the K-means class according the seasonal rice cropping pattern. Finally, we prepared the Boro, Aus and Amon season rice map over the selected ALOS-2 Scan SAR tiles. The crop calendar of Bangladesh has been used for seasonal rice crop detection. We compared our result with relevant study, especially MODIS based rice area of Bangladesh. The overall research flowchart shown in Figure 3.

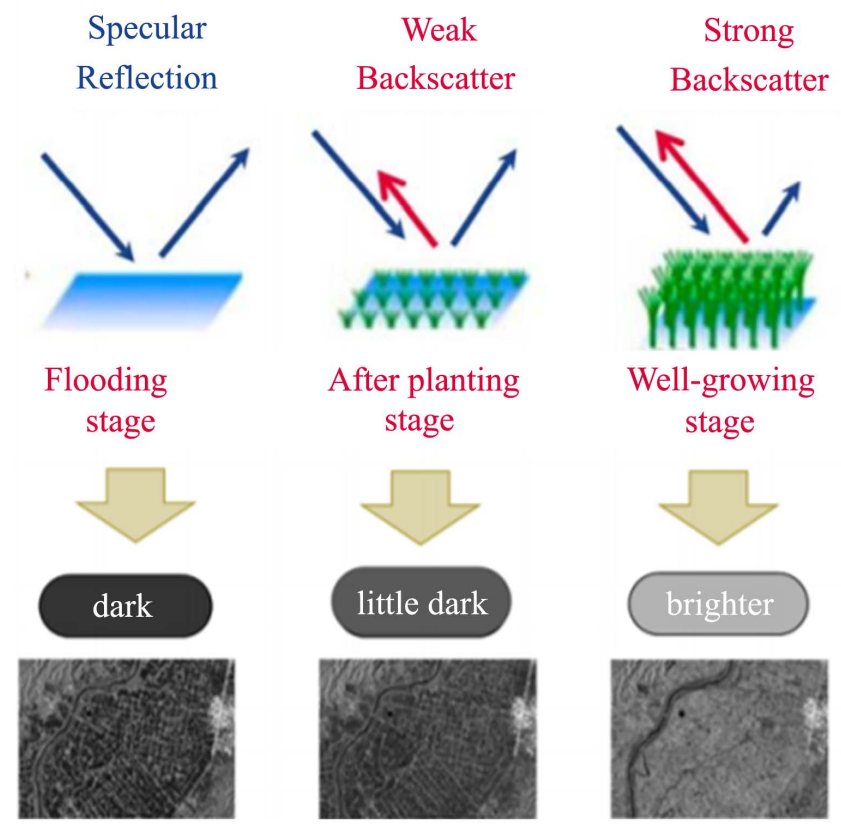

Figure 2. The backscatter reflection of rice paddy field in different growing stage; flooding and transplanting, early grown up and well vegetated rice growing stage. Source: Asian Development Bank. 2017. Innovative Data Collection Methods for Agricultural and Rural Statistics.

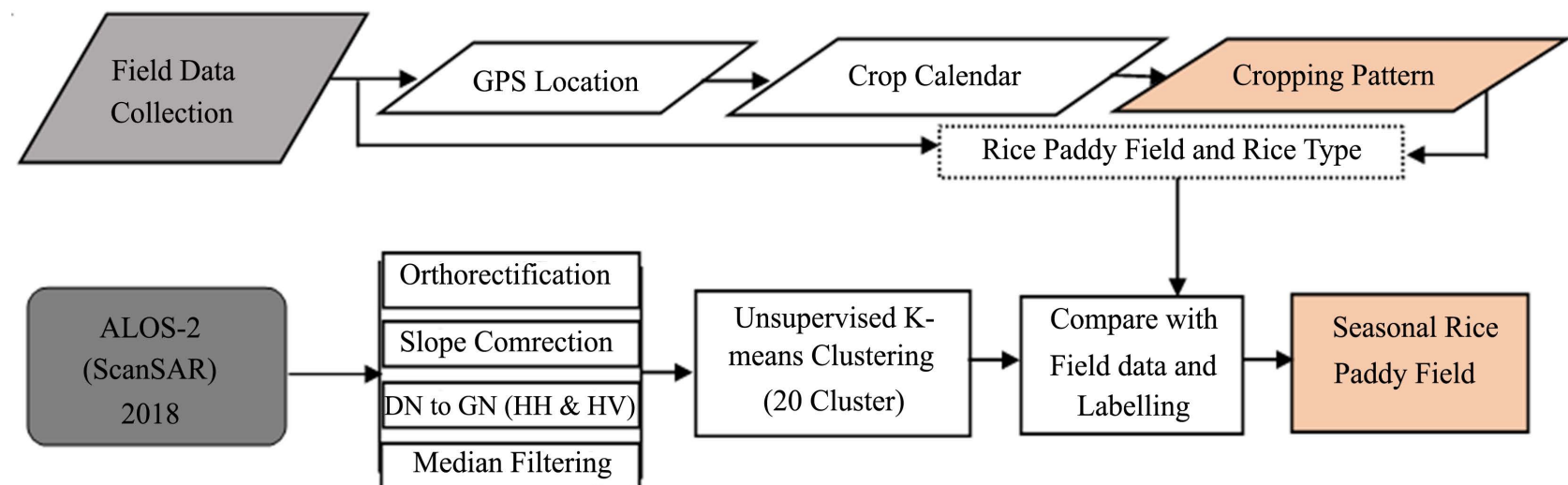

Figure 3. The overall research flowchart composes with ALOS-2 ScanSAR data pre-processing, classification and class extraction with ground truth data with GPS location and cropping pattern over the study area. 


\section{Result and Discussion}

\subsection{K-Means Clustering Result}

The k-means unsupervised classes of the selected tiles of the study area showed the variation among the tiles. The data scene number differences (Satkhira regions 12 scene, Rangpur and Dinajpur regions 18 scene), local physical properties, and landscape variations are probable causes of the variation. The K-means++ 20 classes of the selected tiles with GPS location and cropping pattern of relevant field have been used. The Dinajpur and Satkhira tiles have less GPS ground truth data and less crop area coverage and major part is covered by the mangrove forest Sundarban. As a result, the K-means classes shows less variation and there is no rice crop in class $1,2,4,5,9,12,15,17$ and 19 . Moreover, there is very few GPS ground truth data have collected on this tile as a result the accuracy assessment result may affected. In Dinajpur tiles also less coverage in Bangladesh part and few ground truth data. The K-means class 3, 9, 10, 11, 14 and 18 is absence in this region. The Rangpur tiles is full coverage area with more GPS ground truth data. The ground truth data on Amon-Others, Boro-Amon and Boro-Others cropping pattern are dominated. In this regions K-means classes showed maximum class result. The class 4, 14 and 15 are absence in this region. The field data demonstrated the maximum points in Boro-Aus-Amon and Boro-Amon cropping pattern and less points in Boro-Aus crop pattern. Figure 4 shows the confusion matrix of ALOS-2 and GPS data-based cropping pattern.

\begin{tabular}{|c|c|c|c|c|c|c|c|c|c|c|c|c|c|c|c|c|c|c|c|}
\hline \multirow{2}{*}{$\begin{array}{c}\begin{array}{c}\mathrm{K}- \\
\text { class }\end{array} \\
0\end{array}$} & \multicolumn{3}{|c|}{$\begin{array}{l}\text { Amon- } \\
\text { Others }\end{array}$} & \multicolumn{3}{|c|}{$\begin{array}{l}\text { Boro- } \\
\text { Others }\end{array}$} & \multicolumn{3}{|c|}{$\begin{array}{l}\text { Boro- } \\
\text { Amon }\end{array}$} & \multicolumn{3}{|c|}{ Aus-Others } & \multicolumn{2}{|c|}{ Aus-Amon } & \multicolumn{2}{|c|}{ Boro-Aus } & \multicolumn{3}{|c|}{$\begin{array}{c}\text { Boro-Aus- } \\
\text { Amon }\end{array}$} \\
\hline & & & & & & & & & & 1 & & & & & & 1 & 1 & & \\
\hline 1 & & 2 & 1 & & & 1 & & 3 & 1 & & & 2 & 1 & 2 & & & & & 4 \\
\hline 2 & & & 2 & & & 1 & & 1 & & & & & & & 1 & & & & \\
\hline 3 & & 2 & & & & & & 1 & & & & & 1 & & & & & 1 & \\
\hline 4 & & & 1 & & & 2 & & & 1 & & & & & 1 & & & & & 1 \\
\hline 5 & & 4 & & & & 2 & & 2 & & & & 1 & 3 & & & 1 & & 1 & 1 \\
\hline 6 & & & & & 1 & 1 & 1 & 3 & 1 & 1 & & 1 & 2 & 1 & & & 1 & & 1 \\
\hline 7 & & 2 & 4 & 1 & 1 & & & 2 & 1 & & & 1 & & 1 & & & 1 & 1 & \\
\hline 8 & & 1 & 1 & 1 & 1 & & & 3 & & 2 & 1 & & & & 1 & & & 1 & \\
\hline 9 & & & & & 2 & & & 2 & & & & & & & & & & 4 & \\
\hline 10 & 1 & & & & 2 & & & 2 & & & 2 & & & & 2 & & & 1 & \\
\hline 11 & & 2 & & & & & & & & 1 & & & 1 & & & & 1 & & \\
\hline 12 & & 1 & & & & 1 & & & 2 & & 1 & 1 & & & & & & 1 & \\
\hline 13 & & & & & & & 2 & 1 & & 1 & & 2 & 1 & & & & 2 & 1 & \\
\hline 14 & 2 & & & & & & 2 & & & & & & & & & & & & \\
\hline 15 & & & 1 & & & 2 & & & & & & & & 1 & & & & & 2 \\
\hline 16 & & & 2 & 1 & & & & & 1 & & 2 & & & & & & 2 & & \\
\hline 17 & & 2 & & & 2 & & & 2 & 1 & 1 & 1 & 1 & & & & & & 5 & \\
\hline 18 & & & & & 1 & & & 2 & & & & 1 & & & & & & 3 & \\
\hline 19 & 1 & 3 & 2 & 1 & 1 & 1 & & 4 & & & & & & & & & 2 & 4 & 2 \\
\hline
\end{tabular}

Figure 4. The confusion matrix of ALOS-2 images K-means classes comparison with field GPS data and cropping pattern (Others represent others crops as like Potato, Mastered, Onion, green chilies, seasonal vegetables etc.). 


\subsection{ALOS-2 Rice Calendar}

The rice crop calendar of ALOS-2 ScanSAR and GPS field data used rice area map of the selected study area in this study. The three selected regions showed some variation of K-means classes and rice crop pattern class. The Satkhira regions, which have less temporal resolution and few ground truths point and less $\mathrm{K}$-means classes for rice. The estimated Aus rice area seems as dominated rice cropping pattern. Geographically, this region located close to the coastal area and contains huge soil moisture due to the tidal wave, which probable causes of ALOS-2 ScaSAR backscatter reflection affected. The Rangpur and Dinajpur regions showed more K-means class for rice crop pattern. The Boro and Amon rice area is the dominant cropping pattern of this regions. The Boro rice cultivated in dry season and the others crops during this period are Onion, Cron, Sugarcane, Watermelon, Wheat, Green Chile, and various seasonal vegetables. Due to the uniqueness of rice cultivation in flooded condition, the Boro rice area is easily distinguishable from others crop. The Aus rice growing season is mainly huge rainfall and flood season and Jute is the contemporary crop. Sometimes the over rainfall and deep waterlogged in rice paddy field and Jute field lead misclassification of Aus rice. The Amon rice cultivated in late monsoon and post monsoon season and Banana, Lentil, Mastered, and vegetables are the contemporary crops in this season. As a result, Amon rice also showed very good accuracy. Due to the irrigation practices, favourable weather condition and high market demand, the study area practicing single, double and triple rice cropping pattern. In case of single rice and other crops pattern, the rice field is highly distinguishable. The double rice crop and other cropping pattern, the accuracy is lower than the single rice crop associated patten. In the Rangpur and Dinajpur tiles the double and triple rice crop are leading cropping practices. The Sathkhira regions are mainly dominated by single and double crops. The seasonal rice area (Boro, Aus and Amon) rice area map shown in Figure 5.

\subsection{Comparison with MODIS Data}

The ALOS-2 ScanSAR based rice area map of selected tiles compared with the MODIS Kalman's filter NDVI based rice area map of Bangladesh. The result shows the regional variation of accuracy of different rice types. In the Dinajpur and Rangpur regions demonstrated more accuracy than the Satkhira region. The Dinajpur region demonstrated the highest overall accuracy (77.19\%) followed by Satkhira (74.07\%) and Rangpur (73.39\%). The kappa value for Rangpur, Dinajpur and Satkhira are 68.47, 50.73 and 55.99 respectively. In the Dinajpur regions highest producer accuracy demonstrated in Amon-Others crop class (86.67\%) and followed by Aus-Amon, Boro-Others and lowest in case of Boro-Aus-Amon crop pattern. In case of Boro-Aus, the producer accuracy is $100 \%$, due to the only two GPS ground truth data on it. The highest user accuracy in Aus-Others cropping pattern (83.33\%) and lowest in Boro-Amon (66.67\%.). The maximum commission error in Aus-Amon (33.33\%) and minimum in BoroOthers (11.11\%). The overall accuracy $77.19 \%$ and kappa value 50.72. The Rangpur 


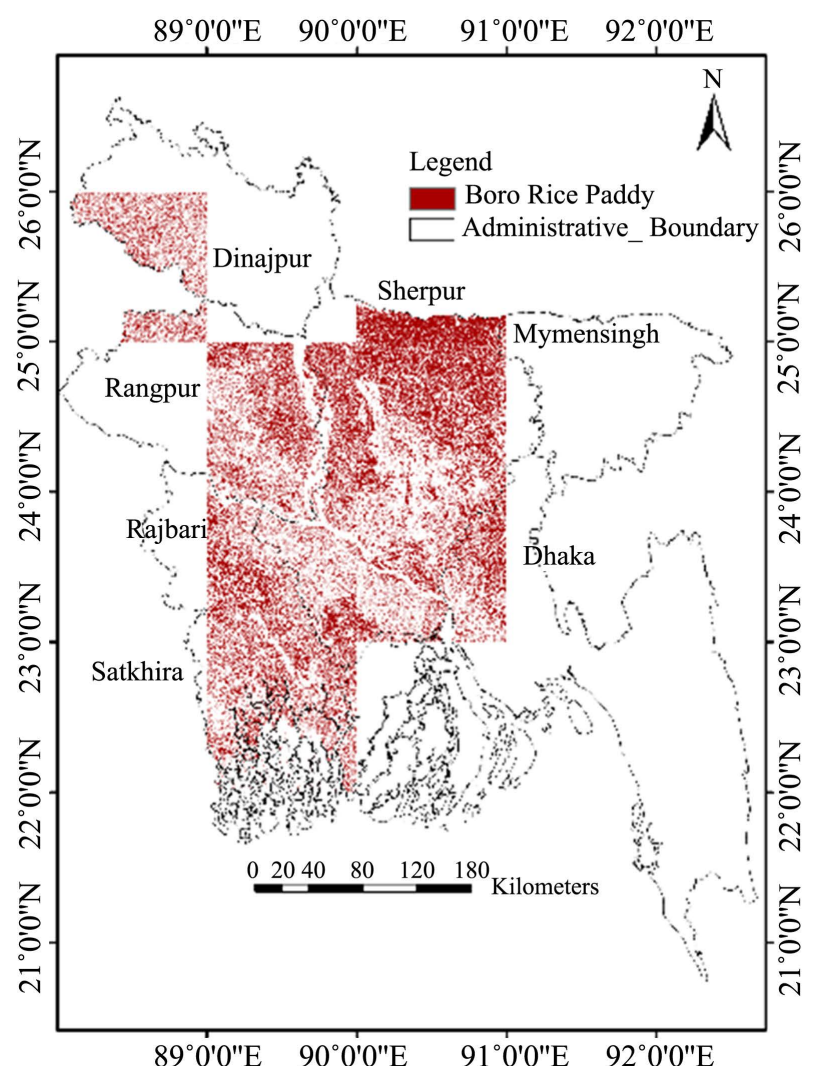

(a)

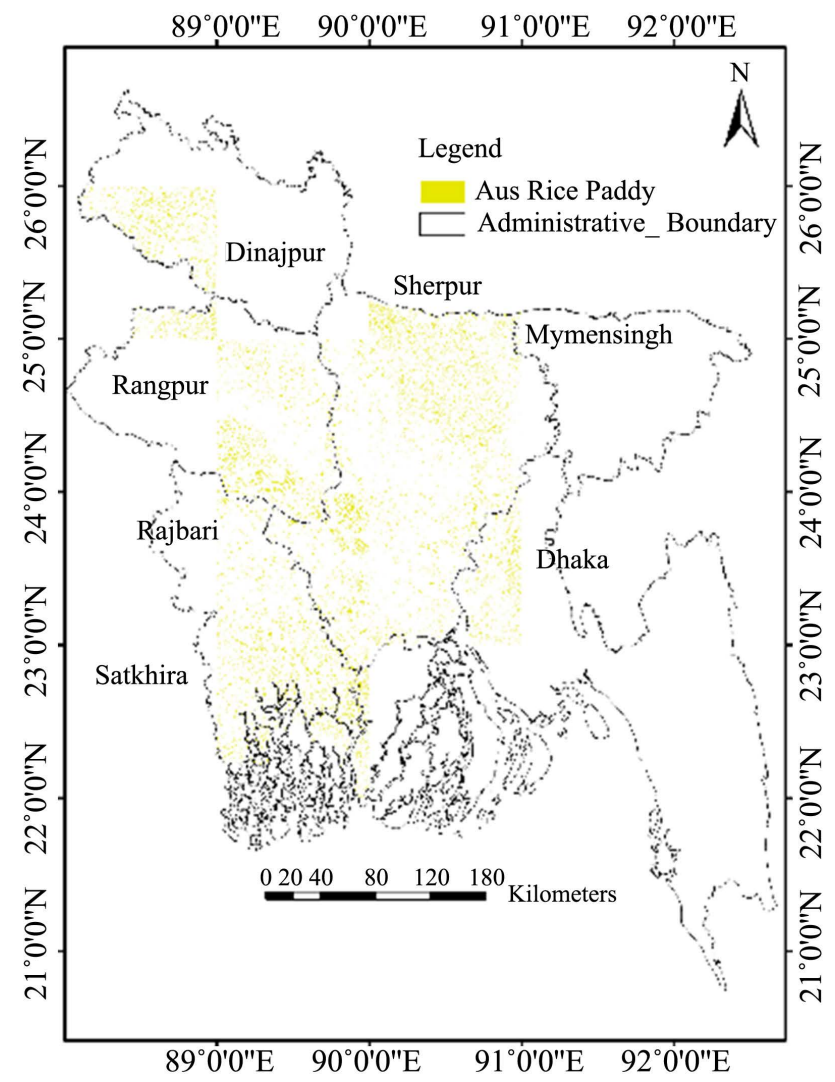

(b) 


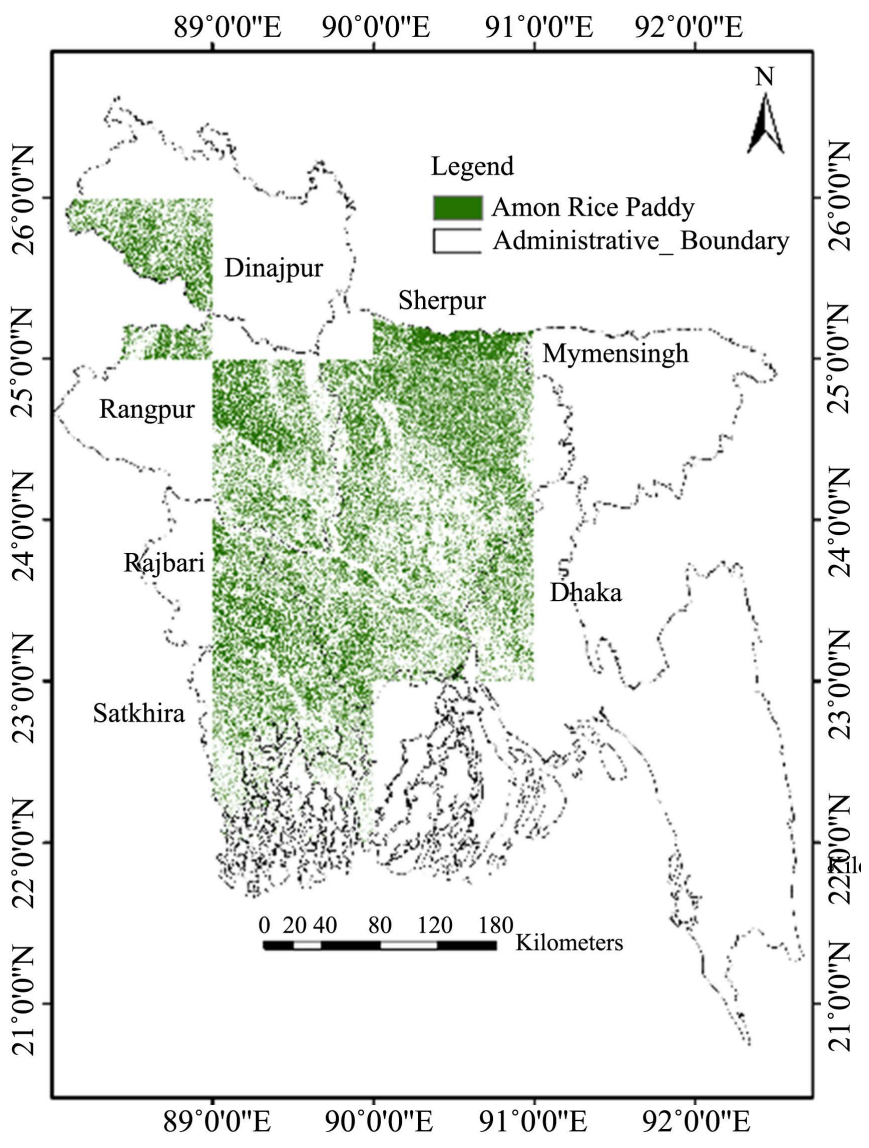

(c)

Figure 5. ALOS-2 ScanSAR based seasonal rice cropping pattern over the selected tiles in Bangladesh, (a) Boro season rice map, Boro Rice Paddy-2018; (b) Amon season rice map, Aus Rice Paddy-2018; and (c) Aus season rice map, Amon Rice Paddy-2018.

tiles maximum producer accuracy in Boro-Others cropping pattern $(90.91 \%)$ and minimum in Boro-Aus-Amon cropping pattern (59.09\%). The Boro-Amon and Aus-Others crops pattern shows highest user accuracy. The lowest omission error in Boro-Others crops types (9.09\%) and highest in Boro-Aus-Amon (40\%). The overall accuracy is $73.39 \%$ and kappa value 68.47 . In the Satkhira tiles the overall accuracy is $74.07 \%$ and kappa value 55.99. In terms of overall commission error, the Boro rice showed lowest and Aus-Amon is highest one. The error matrix of Satkhira and Dinajpur greatly reflected due to the very few ground truth data. The regional variation of physical properties also another probable causes of the variation. The overall accuracy assessment result demonstrated in Figure 6.

\subsection{ALOS-2 ScanSAR Rice Area Map Validation with Field Data and National Statistics}

The ALOS-2 ScanSAR derived seasonal rice area map of selected seven tiles validated with the collected GPS filed data. The field data point compared with the ALOS-2 ScanSAR based rice area map. Among the 35 GPS points of amon rice 


\begin{tabular}{|c|c|c|c|c|c|c|c|c|c|c|c|c|}
\hline \multirow[t]{2}{*}{ Class } & \multicolumn{3}{|c|}{$\begin{array}{l}\text { Producer Accuracy } \\
\text { (\%) }\end{array}$} & \multicolumn{3}{|c|}{$\begin{array}{c}\text { User Accuracy } \\
\text { (\%) }\end{array}$} & \multicolumn{3}{|c|}{$\begin{array}{c}\text { Commission } \\
(\%)\end{array}$} & \multicolumn{3}{|c|}{$\begin{array}{l}\text { Omission } \\
(\%)\end{array}$} \\
\hline & Ran & Din & Sat & Ran & Din & Sat & Ran & Din & Sat & Ran & Din & Sat \\
\hline $\begin{array}{l}\text { Amon- } \\
\text { Others }\end{array}$ & 73.68 & 86.66 & 75.00 & 66.67 & 86.67 & 75.00 & 33.33 & 13.33 & 25.00 & 26.39 & 13.33 & 25.00 \\
\hline $\begin{array}{l}\text { Boro- } \\
\text { Others }\end{array}$ & 90.90 & 80.00 & 66.66 & 58.83 & 88.87 & 80.00 & 41.17 & 11.11 & 20.00 & 9.09 & 30.00 & 33.33 \\
\hline $\begin{array}{l}\text { Boro- } \\
\text { Amon }\end{array}$ & 76.92 & 62.50 & 60.00 & 81.08 & 62.5 & 75.00 & 18.92 & 33.33 & 25.00 & 23.08 & 37.5 & 40.00 \\
\hline $\begin{array}{c}\text { Aus- } \\
\text { Others }\end{array}$ & 71.42 & 70.00 & 80.00 & 83.33 & 77.78 & 66.67 & 16.67 & 22.22 & 33.33 & 28.57 & 30.00 & 20.00 \\
\hline $\begin{array}{l}\text { Aus- } \\
\text { Amon }\end{array}$ & 62.5 & 83.33 & 0.00 & 71.47 & 71.43 & 0 & 28.57 & 33.33 & 0 & 37.50 & 16.67 & 0 \\
\hline $\begin{array}{l}\text { Boro- } \\
\text { Aus }\end{array}$ & 100.0 & 100 & 100 & 75.00 & 66.67 & 66.67 & 25.00 & 50.00 & 33.33 & 33.33 & 50.00 & 0 \\
\hline $\begin{array}{l}\text { Boro- } \\
\text { Aus- } \\
\text { Amon }\end{array}$ & 59.09 & 66.66 & 80.00 & 76.47 & 66.67 & 80.00 & 23.52 & 28.57 & 20.00 & 40.91 & 33.33 & 20.00 \\
\hline
\end{tabular}

Figure 6. The different accuracy assessment indices for the rice paddy field comparison between ALOS-2 and MODIS based rice area in three different study area.

field data, 27 points classified amon rice paddy field, 2 fields are misclassified as boro and amon rice, 3 fields as aus rice and 3 fields as aus and amon rice crop field in ALOS-2 ScanSAR rice map. The probable misclassification between amon and aus rice class is late amon and early aus planted rice paddy field. The single amon to double boro and amon rice paddy fields and aus and amon rice field misclassified is mainly due to the field size change in the different season. Among the total 48 points of boro rice paddy field data, 38 GPS points on boro rice identified as boro and 2 points misclassified as boro and amon rice field, 3 points as aus rice field, 4 points as boro and aus rice and 1 point as amon rice paddy field. Among the 32 GPS point on aus rice field data, 24 points classified as aus rice field and other points are misclassified as amon rice, boro rice, and boro and amon rice field in ALOS-2 ScanSAR rice paddy map. Among the 71 points on boro and amon rice paddy field, 61 points identified as amon and misclassified 3 of them as boro rice, 2 as amon rice, 3 as boro, amon and aus rice paddy field. The higher user's and producer's accuracy found at boro-amon rice pattern are $84.72 \%$ and $85.91 \%$ respectively. The more GPS point, the most common rice cropping pattern are the probable causes of higher accuracy. The lower producer's and user's accuracy in the boro-aus rice cropping pattern and the probable causes are the rarely cultivated pattern and fragmented small field size. The aus rice paddy also shows lower accuracy (70.59\%) as the fluctuated planting date in between boro and amon rice-growing season and misclassified as boro and amon rice paddy field. The double and triple rice cropping pattern also illustrated comparatively lower accuracy mostly due to the changing field size from one season to another. The overall accuracy between the GPS field data and ALOS-2 ScanSAR rice paddy map is $78.65 \%$ with the kappa value 0.76 . Table 1 demonstrated the detail error matrix. 
Table 1. Accuracy assessment of GPS field plot data and ALOS-2 ScanSAR based seasonal rice paddy map over the study area, 2018.

\begin{tabular}{cccccccccc}
\hline \multirow{2}{*}{$\begin{array}{c}\text { Classified } \\
\text { Data }\end{array}$} & Amon & Boro & B-A & Aus & A-A & B-A & B-A-A & $\begin{array}{c}\text { Classified } \\
\text { Total }\end{array}$ & $\begin{array}{c}\text { User's } \\
\text { Accuracy }\end{array}$ \\
\cline { 2 - 9 } & 27 & 1 & 2 & 2 & 0 & 2 & 0 & 34 & 79.41 \\
Amon & 0 & 38 & 3 & 2 & 0 & 2 & 0 & 45 & 84.44 \\
Boro & 2 & 2 & 61 & 2 & 3 & 1 & 1 & 72 & 84.72 \\
B-A & 3 & 3 & & 24 & 1 & 3 & 0 & 34 & 70.59 \\
Aus & 3 & 0 & 1 & 0 & 16 & & 2 & 22 & 72.73 \\
A-A & 0 & 4 & 1 & 2 & 1 & 13 & 1 & 22 & 59.09 \\
B-A & 0 & 0 & 3 & 0 & 4 & 0 & 31 & 38 & 81.57 \\
B-A-A & 35 & 48 & 71 & 32 & 25 & 21 & 35 & 267 & \\
Reference Total & & & & & & & & Overall Accuracy $=0.7865$, \\
Producer's & 77.14 & 79.17 & 85.91 & 75.00 & 64.00 & 61.90 & 88.57 & Kappa = 0.7622 \\
Accuracy & & & & & & & &
\end{tabular}

(Here, B-A = Boro-Amon Rice, A-A = Aus-Amon Rice, B-A = Boro-Aus Rice, B-A-A = Boro-Aus-Amon Rice).

Moreover, the ALOS-2 ScanSAR seasonal rice area in major administrative boundary level compared with the Bangladesh Bureau of Statistics (BBS) reported rice area statistics [24]. Among the administrative boundary, the Mymensingh district is the top rice-producing area. The estimated amon rice area and reported amon and boro rice area are almost same, whereas the estimated aus rice area is overestimated in the district. Similarly, in the case of other districts, the estimated and reported amon and boro rice area showed higher agreement. But the estimated and reported aus rice area demonstrated overvalued and higher discrepancy. The ALOS-2 ScanSAR amon rice area and the BBS reported rice area is shown very good agreement $(\mathrm{R} 2=0.98)$ followed by boro $(\mathrm{R} 2=0.94)$ and aus $(\mathrm{R} 2=0.71)$ in the selected administrative district level. The total estimated and reported amon rice area is 1,017,983 ha and 995,505 ha, respectively in the study area. The boro area also showed good agreement whereas reported area is 1,101,538 ha and estimated area 1,029,036 ha. The aus rice area shows higher discrepancy between the reported and estimated area (Table 2).

Table 2. Comparison of seasonal ALOS-2 ScanSAR estinmated rice area with national statistics by administrative districs.

\begin{tabular}{ccccccccc}
\hline \multirow{2}{*}{ District } & \multicolumn{3}{c}{ ALOS-2 Estimated rice area (ha) } & \multicolumn{4}{c}{ BBS Reported rice area (ha) } \\
\cline { 2 - 8 } & \multicolumn{3}{c}{ Boro Rice Aus Rice Amon Rice } & Total & Boro Rice Aus Rice Amon Rice & Total \\
\hline Dhaka & 35,361 & 5448 & 32,986 & 73,795 & 47,156 & 747 & 16,716 & 64,619 \\
Faridpur & 44,309 & 9997 & 83,172 & 137,478 & 27,804 & 6580 & 82,090 & 116,474 \\
Gazipur & 48,218 & 2796 & 36,963 & 87,977 & 54,316 & 1356 & 42,502 & 98,174 \\
Madaripur & 26,218 & 2813 & 31,631 & 60,662 & 33,677 & 1525 & 26,511 & 61,713 \\
\hline
\end{tabular}




\begin{tabular}{|c|c|c|c|c|c|c|c|c|}
\hline \multicolumn{9}{|l|}{ Continued } \\
\hline Manikgonj & 36,481 & 1752 & 43,652 & 81,885 & 46,533 & 142 & 38,891 & 85,566 \\
\hline Munshigonj & 36,377 & 845 & 29,138 & 66,360 & 26,450 & 940 & 20,745 & 48,135 \\
\hline Narayangonj & 25,106 & 4578 & 20,361 & 50,045 & 26,018 & 690 & 10,883 & 37,591 \\
\hline Narshingdi & 43,892 & 6127 & 42,720 & 92,739 & 50,213 & 331 & 41,483 & 92,027 \\
\hline Mymensingh & 271,349 & 41,233 & 257,157 & 569,739 & 266,243 & 16,626 & 259,040 & 541,909 \\
\hline Rajbari & 22,488 & 5539 & 38,712 & 66,739 & 12,664 & 1310 & 46,256 & 60,230 \\
\hline Shariatpur & 34,911 & 4634 & 26,610 & 66,155 & 21,172 & 9180 & 17,689 & 48,041 \\
\hline Tangail & 153,148 & 9931 & 122,680 & 285,759 & 191,878 & 837 & 116,482 & 309,197 \\
\hline Magura & 40,850 & 3075 & 51,254 & 95,179 & 42,696 & 3310 & 58,715 & 104,721 \\
\hline Narail & 43,826 & 5561 & 37,737 & 87,124 & 59,063 & 5459 & 39,975 & 104,497 \\
\hline Pabna & 68,888 & 24,759 & 85,268 & 178,915 & 56,317 & 16,974 & 94,727 & 168,018 \\
\hline Sirajgonj & 97,614 & 6455 & 77,942 & 182,011 & 139,338 & 4725 & 82,800 & 226,863 \\
\hline Total & $1,029,036$ & 135,543 & $1,017,983$ & $2,182,562$ & $1,101,538$ & 70,732 & 995,505 & $2,167,775$ \\
\hline
\end{tabular}

\section{Conclusion}

The multi dated ALOS-2 ScanSAR data with unsupervised classification and supervised labeling used for seasonal rice paddy. The methodology shows very good accuracy (59\% to $84 \%$ ) to identify even the complex rice cropping pattern. The rice crop calendar mapping with ALOS- 2 based rice paddy mapping showed a great potential for seasonal cloud affected region like Bangladesh. The K-means class ScanSAR data with GPS ground truths data detected the seasonal rice crop calendar with high accuracy. Although, the temporal and spatial resolution variation between the ALOS2 and MODIS based rice area map. The producer accuracy varies from $62 \%$ to $90 \%$ in different regions and boro rice in Rangpur demonstrated $90 \%$ accuracy. The result showed $66 \%$ to $88 \%$ user accuracy from region to region and similar to producer accuracy boro rice showed maximum user accuracy.

\section{Conflicts of Interest}

The author declares no conflicts of interest regarding the publication of this paper.

\section{References}

[1] World Data Bank World Development Indicators. DataBank. https://databank.worldbank.org/reports.aspx? source $=2 \&$ series=EN.ATM.METH.K T.CE\&country=\#selectedDimension WDI Ctry

[2] Majumder, S., Bala, B.K., Arshad, F.M., Haque, M.A. and Hossain, M.A. (2016) Food Security through Increasing Technical Efficiency and Reducing Postharvest Losses of Rice Production Systems in Bangladesh. Food Security, 8, 361-374. https://doi.org/10.1007/s12571-016-0558-x

[3] FAOSTAT: FAO Statistical Databases (Food and Agriculture Organization of the 
United Nations) Databases.

[4] Islam, R. and Hassn, Z. (2013) Losses of Agricultural Land Due to Infrastructural Development: A Study on Rajshahi District. International Journal of Scientific and Engineering Research, 4, 391-397.

[5] Hossain, M.B., Yesmin, S., Maniruzzaman, M. and Biswas, J.C. (2017) Irrigation Scheduling of Rice (Oryza sativa L.) Using CROPWAT Model in the Western Region of Bangladesh. The Agriculturists, 15, 19-27. https://doi.org/10.3329/agric.v15i1.33425

[6] Food and Agriculture Organization of the United Nations Bangladesh AQUASTAT Data. 2014, 1-16.

[7] Mosleh, M.K., Hassan, Q.K. and Chowdhury, E.H. (2015) Application of Remote Sensors in Mapping Rice Area and Forecasting Its Production: A Review. Sensors (Switzerland), 15, 769-791. https://doi.org/10.3390/s150100769

[8] Shapla, T., Park, J., Hongo, C. and Kuze, H. (2015) Change Detection of Rice Cultivation in Bangladesh Based on the Phenological Analysis of MODIS Data. Advanced Remote Sensing, 4, 319-329. https://doi.org/10.4236/ars.2015.44026

[9] Long, J.A., Lawrence, R.L., Greenwood, M.C., Marshall, L. and Miller, P.R. (2013) Object-Oriented Crop Classification Using Multitemporal ETM+ SLC-Off Imagery and Random Forest. GIScience \& Remote Sensing, 50, 418-436. https://doi.org/10.1080/15481603.2013.817150

[10] Zhang, Y., Wang, C., Wu, J., Qi, J. and Salas, W.A. (2009) Mapping Paddy Rice with Multitemporal ALOS/PALSAR Imagery in Southeast China. International Journal of Remote Sensing, 30, 6301-6315. https://doi.org/10.1080/01431160902842391

[11] Zhang, G., Xiao, X., Dong, J., Kou, W., Jin, C., Qin, Y., Zhou, Y., Wang, J., Angelo Menarguez, M. and Biradar, C. (2015) Mapping Paddy Rice Planting Areas through Time Series Analysis of MODIS Land Surface Temperature and Vegetation Index Data HHS Public Access. ISPRS Journal of Photogrammetry and Remote Sensing, 106, 157-171. https://doi.org/10.1016/j.isprsjprs.2015.05.011

[12] Liao, J., Hu, Y., Zhang, H., Liu, L. and Liu, Z. (2018) A Rice Mapping Method Based on Time-Series Landsat Data for the Extraction of Growth Period Characteristics. Sustainability, 10, 2570. https://doi.org/10.3390/su10072570

[13] Gumma, M.K., Thenkabail, P.S., Maunahan, A., Islam, S. and Nelson, A. (2014) Mapping Seasonal Rice Cropland Extent and Area in the High Cropping Intensity Environment of Bangladesh Using MODIS $500 \mathrm{~m}$ Data for the Year 2010. ISPRS Journal of Photogrammetry and Remote Sensing, 91, 98-113.

https://doi.org/10.1016/j.isprsjprs.2014.02.007

[14] Gumma, M.K. (2011) Mapping Rice Areas of South Asia Using MODIS Multitemporal Data. Journal of Applied Remote Sensing, 5, Article ID: 053547. https://doi.org/10.1117/1.3619838

[15] Guan, K., Li, Z., Rao, L.N., Gao, F., Xie, D., Hien, N.T. and Zeng, Z. (2018) Mapping Paddy Rice Area and Yields over Thai Binh Province in Vietnam from MODIS, Landsat, and ALOS-2/PALSAR-2. IEEE Journal of Selected Topics in Applied Earth Observations and Remote Sensing, 11, 2238-2252. https://doi.org/10.1109/JSTARS.2018.2834383

[16] Zhu, Z., Woodcock, C.E., Rogan, J. and Kellndorfer, J. (2012) Assessment of Spectral, Polarimetric, Temporal, and Spatial Dimensions for Urban and Peri-Urban Land Cover Classification Using Landsat and SAR Data. Remote Sensing of Environment, 117, 72-82. https://doi.org/10.1016/j.rse.2011.07.020

[17] Dong, J. and Xiao, X. (2016) Evolution of Regional to Global Paddy Rice Mapping 
Methods: A Review. ISPRS Journal of Photogrammetry and Remote Sensing, 119, 214-227. https://doi.org/10.1016/j.isprsjprs.2016.05.010

[18] Lee, J. (1986) Sen Speckle Suppression and Analysis for Synthetic Aperture Radar Images. Optical Engineering, 25, 636-643. https://doi.org/10.1117/12.7973877

[19] Singha, M., Dong, J., Zhang, G. and Xiao, X. (2019) High Resolution Paddy Rice Maps in Cloud-Prone Bangladesh and Northeast India Using Sentinel-1 Data. Scientific Data, 6, 26. https://doi.org/10.1038/s41597-019-0036-3

[20] Nguyen, D.B., Clauss, K., Cao, S., Naeimi, V., Kuenzer, C. and Wagner, W. (2015) Mapping Rice Seasonality in the Mekong Delta with Multi-Year Envisat ASAR WSM Data. Remote Sensing, 7, 15868-15893. https://doi.org/10.3390/rs71215808

[21] Mohite, J.D., Sawant, S.A., Kumar, A., Prajapati, M., Pusapati, S.V., Singh, D. and Pappula, S. (2018) Operational near Real Time Rice Area Mapping Using Multi-Temporal Sentinel-1 SAR Observations. Proceedings of the International Archives of the Photogrammetry, Remote Sensing and Spatial Information SciencesISPRS Archives, Vol. 42, 507-514.

https://doi.org/10.5194/isprs-archives-XLII-4-433-2018

[22] BMD (Bangladesh Meterological Department) (2017) Bangladesh Meterological Department, Dhaka.

[23] FAO (2016) F. Country Fact Sheet on Food and Agriculture Policy Trends-United Republic of Tanzania.

[24] (2018) BBS Agricultural Statistical Yearbook of Bangladesh, Dhaka. 